\title{
Interleukin 6 (rs1800795) and Pentraxin 3 (rs2305619) Polymorphisms - Association with Inflammation and All-Cause Mortality in End-stage- renal Disease Patients on Dialysis
}

\section{Susana Rocha}

LAQV, REQUIMTE, Laboratório de Química Aplicada, Departamento de Ciências Químicas, Faculdade de Farmácia da Universidade do Porto, Porto, Portugal

Maria João Valente

UCIBIO, REQUIMTE, Laboratório de Bioquímica, Departamento de Ciências Biológicas, Faculdade de Farmácia da Universidade do Porto, Porto, Portugal

\section{Susana Coimbra}

CESPU, Instituto de Investigação e Formação Avançada em Ciências e Tecnologias da Saúde (IINFACTS), Gandra Paredes, Portugal

\section{Cristina Catarino}

UCIBIO, REQUIMTE, Laboratório de Bioquímica, Departamento de Ciências Biológicas, Faculdade de Farmácia da Universidade do Porto, Porto, Portugal

\section{Petronila Rocha-Pereira}

Universidade da Beira Interior, Centro de Investigação em Ciências da Saúde, Covilhã, Portugal

José Gerardo Oliveira

Centro de Investigação em Tecnologias de Saúde (CINTESIS), Faculdade de Medicina da Universidade do Porto,

\section{José Madureira}

NefroServe, Centro de Hemodiálise de Nossa Senhora da Franqueira, Barcelos,

\section{João Carlos Fernandes}

NefroServe, Centro de Hemodiálise de Viana do Castelo, Viana do Castelo,

\section{Maria Sameiro-Faria}

Unidade de Hemodiálise, Hospital Agostinho Ribeiro, Felgueiras, Felgueiras,

\section{Vasco Miranda}

Clínica de Hemodiálise de Gondomar, Gondomar,

\section{Luís Belo}

UCIBIO, REQUIMTE, Laboratório de Bioquímica, Departamento de Ciências Biológicas, Faculdade de Farmácia da Universidade do Porto, Porto, Portugal 
UCIBIO, REQUIMTE, Laboratório de Bioquímica, Departamento de Ciências Biológicas, Faculdade de Farmácia da Universidade do Porto, Porto, Portugal

Elsa Bronze-da-Rocha ( $\nabla$ elsa.rocha@ff.up.pt )

UCIBIO, REQUIMTE, Laboratório de Bioquímica, Departamento de Ciências Biológicas, Faculdade de Farmácia da Universidade do Porto, Porto, Portugal

\section{Research Article}

Keywords: IL6 polymorphism, PTX3 polymorphism, End-stage renal disease (ESRD), inflammation, allcause mortality risk

Posted Date: April 6th, 2021

DOl: https://doi.org/10.21203/rs.3.rs-378173/v1

License: (c) (i) This work is licensed under a Creative Commons Attribution 4.0 International License. Read Full License

Version of Record: A version of this preprint was published at Scientific Reports on July 20th, 2021. See the published version at https://doi.org/10.1038/s41598-021-94075-x. 


\section{Abstract}

Chronic inflammation plays an important role in the progression and outcome of chronic kidney disease (CKD). The inflammatory biomarkers interleukin-6 (IL6) and pentraxin 3 (PTX3) are enhanced in CKD patients and associated with progression of the disease and higher risk for cardiovascular events, the major cause of death in these patients. Our aim was to study how the polymorphisms of their encoding genes affect the inflammatory response and outcome of end-stage renal disease (ESRD) patients on dialysis.

We analyzed two single nucleotide polymorphisms (SNP), the IL6 (rs1800795) polymorphism in the promoter region $(-174 \mathrm{G} / \mathrm{C})$, and the PTX3 polymorphism in the intron $1(+281 \mathrm{~A} / \mathrm{G})$, in ESRD patients on dialysis and in heathy individuals. The allelic frequencies, genotype distribution and their association with the circulating levels of the inflammatory markers high sensitivity C-reactive protein (hSCRP), interleukin (IL6), growth differentiation factor 15 (GDF15) and PTX3, were determined in ESRD patients; events of death were recorded along one year to evaluate all-cause mortality and the association between inflammation and the studied polymorphisms.

The allelic frequencies and genotyping distribution for IL6 and PTX 3 in controls and ESRD patients were similar and in agreement with European reports. For the IL6 polymorphism, we found an association of the GG and CC genotype with higher IL6 levels; the CC genotype showed also high PTX3, hsCRP and GDF15 levels. For the PTX3 polymorphism, the AA genotype was linked to the highest values of hsCRP and IL6. The mortality rate after 1-year follow-up was 10.4\%. The CC genotype (IL6 polymorphism), in deceased patients, was associated to increased levels of hsCRP, IL6 and PTX3, with low levels of GDF15 and with a highest mortality risk. The AA genotype for PTX3 polymorphism, in spite of the enhancement in inflammation, showed no significant impact on mortality.

Our results show that the CC genotype of the IL6 polymorphism was associated with an enhanced inflammatory state and a poorer survival rate. Both IL6 and PTX3 polymorphisms seem to modulate the inflammatory response and, therefore, disease progression and outcome. Our data also highlights the importance of research on genetic variants that, although less frequent, may have significant biological value.

\section{Introduction}

Chronic kidney disease (CKD) is characterized by a progressive loss of renal function, measured by a decline in the estimated glomerular filtration rate (eGFR), that aggravates from stage 1 to the terminal stage 5, end-stage renal disease (ESRD), which requires kidney replacement therapy (KRT) through transplantation or dialysis. The number of patients requiring KRT has been predicted to rise $60 \%$ from 2011 until $2020^{1-3}$. By 2010, the number of ESRD patients undergoing KRT worldwide exceeded 2.6 million ( $78 \%$ on dialysis and $22 \%$ with a kidney transplant), and this number was projected to rise up to 5.4 million by $2030^{4}$. CKD represents, thus, a major public health problem worldwide. 
Inflammation is a common feature in patients with CKD that usually increases with the severity of the disease. C-reactive protein (CRP), growth differentiation factor 15 (GDF15), pentraxin 3 (PTX3) and interleukin (IL6) are inflammatory mediators that are increased in CKD patients, and particularly enhanced in patients on hemodialysis (HD).

CRP is an acute phase protein and a potential predictor of cardiovascular morbidity and mortality in CKD patients on $\mathrm{HD}^{5,6}$.

GDF15 is a member of the transforming growth factor- $\beta$ (TGF- $\beta$ ) cytokine superfamily that has been associated with inflammation, diabetes mellitus, atherosclerosis, cardiovascular disease, and proposed as a strong risk factor for poor outcome and mortality in CKD patients ${ }^{7-12}$.

The long PTX3 is associated with kidney dysfunction and disease activity, as well as with the severity of other inflammatory, cardiovascular and autoimmune diseases. Increased levels of PTX 3 in CKD patients have been also connected to the rise in other inflammatory markers, such as CRP, tumor necrosis factoralpha (TNF-a), IL6, and soluble vascular cell adhesion molecule $1^{13,14}$. The evaluation of PTX3 might be useful for monitoring CKD and to identify and treat early-stage subclinical atherosclerosis in these patients ${ }^{6,13-16}$.

IL6 is a pro-inflammatory cytokine that mediates the release of other cytokines, enhancing the inflammatory response in several diseases, as occurs in CKD. The accumulation of uremic toxins, fluid overload, the development of oxidative stress, among other CKD disturbances, contribute to the rise in IL6; the decreased renal function, by reducing IL6 clearance, also contributes to the increase in its levels. Likewise, the HD and peritoneal dialysis procedures contribute to stimulate the inflammatory response, further increasing IL6 production. The continuous high levels of inflammatory cytokines, such as IL6, in CKD patients, have been associated with a high risk for cardiovascular diseases (CVD), which are the major cause of death in these patients $5,6,17-20$.

There are several genes correlated with biochemical and inflammatory markers in CKD, and their genetic variants were associated with kidney (dys)function and with the prevalence of CKD 1,21,22. However, the relationship between the genetic polymorphisms of some inflammatory markers and the outcome of CKD patients is not completely clarified.

The human IL6 gene is located on chromosome 7p21, has 5 exons and 4 introns and several polymorphisms in the promoter region [IL6 (-174G/C: rs1800795, IL6 (-572G/C): rs1800796, IL6 (-597G/A): rs1800797, and IL6 (-634C/G) ${ }^{23}$. Different studies in ESRD patients on dialysis treatment reported the contribution of IL6 allelic variants in the promotor region to the variation/modulation of several biochemical and clinical parameters, such as serum erythropoietin, hemoglobin concentration ${ }^{24}$, inflammatory biomarkers ${ }^{25}$, dysfunction in the vascular access for HD procedure ${ }^{26}$, progression of kidney dysfunction ${ }^{27}$, and in the risk for CVD, coronary artery disease ${ }^{28,29}$, and atherosclerosis ${ }^{30}$. 
However, the influence of IL6 genetic variants in the inflammatory response, outcome and mortality risk in ESRD still needs more research.

PTX3 is produced by mononuclear phagocytes, dendritic cells, fibroblasts, macrophages, smooth muscle cells, adipocytes and endothelial cells ${ }^{14}$. The human PTX3 gene, located on the long arm of chromosome 3 (q24-28), presents a 5'-UTR and 3'-UTR regions, two introns and three exons ${ }^{14,31,32}$. The PTX3 polymorphism (+281A/G) (rs2305619) is located at intron 1 (boundary) ${ }^{33}$. PTX3 genetic variants [PTX3 (+ 1449 A/G), second intron: rs1840680, PTX3 (+ 734A/C), second exon: rs3816527, and PTX3 (C > A) 5'-UTR: rs2120243] have been associated with several clinical conditions, such as infections, female fertility, risk and progression of oral cancer ${ }^{34}$, type II diabetes nephropathy ${ }^{35}$, hypertension ${ }^{36}$ and migraine ${ }^{37}$. Circulating levels of PTX3 are elevated in CKD patients, and appear to independently predict cardiovascular complications, both in dialysis and pre-dialysis patients ${ }^{6}$. Still, few studies investigated the association of PTX3 polymorphisms with inflammatory markers of ESRD.

The purpose of this study was to determine the allelic frequencies and genotype distribution of specific IL6 and PTX-3 polymorphisms in a Portuguese cohort of ESRD patients on dialysis and in healthy individuals (controls). We aimed to identify the association of the genetic variants of IL6 (rs1800795), located in the IL6 promoter region, and of PTX3 (rs2305619), positioned in the first intron (boundary), with some biomarkers of inflammatory response, namely, IL6, CRP, GDF15 and PTX3. After one-year follow-up, recording the events of death, we also analyzed the influence of these polymorphisms on allcause mortality.

\section{Material And Methods}

\section{Subjects}

The studies involving human samples and data analysis, presented in thesubmitted manuscript, were approved by the Ethics Committee from the Facultyof Pharmacy, University of Porto (Report N ${ }^{\circ} 26-04-$ 2016), in accordance withrelevant guidelines and regulations. The project was also approved by

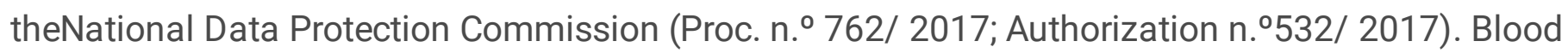
samples were collected after informed consent of all participants. Patients with known recent trauma, neoplastic diseases, active infectious diseases or undergoing dialysis for less than 90 days, were excluded from the study. Dialysis treatment was performed using FX-class ${ }^{\circledR}$ high-flux polysulfone dialyzers (1.4-2.2 m2) (Fresenius, Germany); only 14.2\% $(n=41)$ were under high-flux hemodialysis, while $85.8 \%$ of patients $(n=248)$ were under online hemodiafiltration. The control group included 32 healthy volunteers, with normal hematological and biochemical data. Clinical data from ESRD patients were collected at the Dialysis Clinics in the beginning of the study, and along the following year, to identify cases of death. Subjects from the control group $[n=32 ; 55.8 \pm 4.8$ years old; 19 (59.4\%) females and $13(40.6 \%)$ males] and ESRD patients $[n=289 ; 68.7 \pm 13.6$ years old; 131 (45.3\%) females and 158 (54.7\%) males] presented similar distribution of gender, and, as far as possible, of age. The main 
etiologies of renal failure were: diabetic nephropathy $[n=101$ (34.9\%)], hypertensive nephrosclerosis $[n=$ $36(12.5 \%)]$, polycystic kidney disease [ $n=19(6.6 \%)]$, chronic glomerulonephritis [ $n=23(8.0 \%)$, other $[n=$ $44(15.2 \%)]$ or undetermined [ $n=66(22.8 \%)]$. The vascular access for HD procedure was performed by central venous catheter $[n=42(14.5 \%)]$, arteriovenous fistula $[n=233(80.6 \%)]$ or arteriovenous graft $[n=$ $14(4.8 \%)]$. A total of 28 deceased patients (10.4\%) was reported over the one-year follow-up period, with miscellaneous causes of death, including cardiovascular causes, cachexia, infectious diseases, or others. During this follow-up period, 21 patients left the study (transplanted, recovered renal function, transferred for another HD Clinic or KRT abandonment).

\section{Samples}

Blood samples, from both controls and patients, were collected into tubes, without and with anticoagulant (K3-EDTA), and processed within 2 hours to obtain serum, plasma and buffy-coat, respectively. Aliquots of plasma, serum and buffy-coat were immediately stored at $-80^{\circ} \mathrm{C}$ until assayed. Sample collection from ESRD patients took place immediately before a midweek dialysis therapy session.

\section{Assays}

All biomarkers were analyzed through commercially available kits, according to the manufacturer's instructions. Plasma samples were used to quantify PTX3 (Human Pentraxin 3/TSG-14 Quantikine ELISA Kit, R\&D Systems, Minnesota, USA) and GDF15 (Human GDF15 ELISA Kit, Abcam, Cambridge, UK) through enzyme-linked immunosorbent assay (ELISA). In serum we measured IL6 by ELISA (Human IL6 Quantikine HS, R\&D Systems, by ELISA) and high-sensitivity (hs)CRP by immunoturbidimetry [Cardiac CReactive Protein (Latex) High Sensitive assay, Roche Diagnostics, Basel, Switzerland].

Genomic DNA was extracted from buffy-coat, using genomic DNA extraction kit (GRiSP, Research Solutions, Porto, Portugal), quantified by NanoDrop ${ }^{T M}-1000$ (ThermoFisher Scientific, Wilmington, DE, USA) and analyzed by agarose gel electrophoresis. Trademark TaqMan® SNP genotyping assays (Human; ThermoFisher Scientific) were performed to assess the allelic frequencies of IL6 (rs1800795) and PTX3 (rs2305619) polymorphisms, using a real-Time PCR system (StepOnePlus, ThermoFisher Scientific).

\section{Statistical Analysis}

Data were analyzed using the IBM SPSS software, version 25 for Windows 10 (IBM, New York, USA). Data distribution was evaluated by the Shapiro-Wilk test. Results are presented as median (interquartile range), since most variables presented a non-Gaussian distribution. For categorical variables, the comparison between groups at baseline was analyzed using the chi-squared test. For continuous variables, 
differences between groups were evaluated using Mann-Whitney Utest. The strength of the correlations between variables was determined through the Spearman's rank correlation coefficient. Survival distribution comparisons between genotypes was performed by the log-rank test. Estimation of all-cause mortality hazard ratio (HR), according to IL6 polymorphisms, was determined by multiple Cox regression analysis. A $p<0.05$ value was considered statistically significant.

\section{Results}

\section{Genotype prevalence and allelic frequencies of IL6 and PTX3 polymorphisms in ESRD patients and controls}

Genotype prevalence and allelic frequencies in ESRD patients and controls were analyzed, for both single nucleotide polymorphisms of IL6 rs1800795 (-174G > C) and of PTX3 rs2305619 (+281A > G) (Table 1).

For IL6 $(-174 G>C)$, the prevalence of CC, GG and CG genotypes, as well as the frequency of both alleles $C$ and $G$ was similar in ESRD patients and in healthy individuals. Likewise, regarding the PTX3 $(+281 A>G)$ polymorphism, the genotype distribution of $A A, G G$ and $A G$ and allelic frequency of $A$ and $G$ did not differ between patients and controls. Additionally, in this cohort of renal patients, the genotype prevalence for both polymorphisms was not altered by gender, etiology of CKD, type of vascular access for dialysis procedure, dialysis vintage, dialysis type, diabetes, hypertension or CVD history (data not shown). 
Table 1

Genotype and allelic distribution of IL6 $(-174 \mathrm{G}>\mathrm{C})$ and PTX3 $(+281 \mathrm{~A}>\mathrm{G})$ polymorphisms in Controls and end-stage renal disease patients on dialysis $(n=32 / 289$, respectively)

\begin{tabular}{|c|c|c|c|}
\hline IL6 $(-174 G>C)$ & Control & ESRD & $p\left(x^{2}\right)$ \\
\hline Genotype & $n ; \%$ & $n ; \%$ & \\
\hline $\mathrm{CC}$ & $3 ; 9.4 \%$ & $28 ; 9.7 \%$ & \multirow[t]{3}{*}{0.819} \\
\hline GG & $17 ; 53.1 \%$ & $137 ; 47.4 \%$ & \\
\hline CG & $12 ; 37.5 \%$ & $124 ; 42.9 \%$ & \\
\hline Allele & Frequency & Frequency & \\
\hline C & 0.28 & 0.31 & \multirow[t]{2}{*}{0.620} \\
\hline G & 0.72 & 0.69 & \\
\hline PTX3 $(+281 A>G)$ & Control & ESRD & $p\left(\chi^{2}\right)$ \\
\hline Genotype & $n ; \%$ & $n ; \%$ & \\
\hline AA & $5 ; 15.6 \%$ & $72 ; 24.9 \%$ & \multirow[t]{3}{*}{0.444} \\
\hline GG & $10 ; 31.3 \%$ & $91 ; 31.5 \%$ & \\
\hline$A G$ & $17 ; 53.1 \%$ & $126 ; 43.6 \%$ & \\
\hline Allele & Frequency & Frequency & \\
\hline A & 0.42 & 0.46 & \multirow[t]{2}{*}{0.491} \\
\hline G & 0.58 & 0.54 & \\
\hline
\end{tabular}

\section{Blood levels of the inflammatory markers and their association with the IL6 (rs1800795) and PTX3 (rs2305619) polymorphisms}

The circulating levels of hsCRP, IL6, PTX3 and GDF15, observed for the different IL6 and PTX3 polymorphic genotypes are presented in Table 2. For the IL6 $(-174 G>C)$ polymorphism, the highest levels of hsCRP, PTX3 and GDF 15 were observed for the CC genotype; however, we only found significantly higher values of hsCRP in CC versus CG genotype, and significantly higher values of GDF15 in CC versus $\mathrm{GG}$, and $\mathrm{CC}$ versus $\mathrm{CG}$ genotypes. 
Table 2

Blood levels of IL6, hsCRP, PTX3 and GDF15, according to the IL6 and PTX3 polymorphic genotype in end-stage renal disease patients $(n=289)$

\begin{tabular}{|c|c|c|c|c|c|c|}
\hline \multirow{2}{*}{ Biomarker } & \multicolumn{3}{|c|}{ IL6 $(-174 G$ > C) genotype } & \multicolumn{3}{|l|}{$p$ value } \\
\hline & $\mathrm{CC}(n=28)$ & $\begin{array}{l}\mathrm{GG}(n= \\
137)\end{array}$ & $\begin{array}{l}\text { CG }(n= \\
124)\end{array}$ & $\begin{array}{l}\text { CC vs. } \\
\text { GG }\end{array}$ & $\begin{array}{l}\text { CC vs. } \\
\text { CG }\end{array}$ & GG vs. CG \\
\hline \multirow[t]{2}{*}{ hsCRP (mg/dL) } & 0.52 & 0.42 & 0.30 & 0.157 & 0.017 & 0.127 \\
\hline & $\begin{array}{l}(0.29- \\
1.09)\end{array}$ & $(0.16-0.82)$ & $(0.13-0.74)$ & & & \\
\hline \multirow[t]{2}{*}{ IL6 (pg/mL) } & 4.23 & 4.45 & 3.68 & 0.433 & 0.095 & 0.144 \\
\hline & $\begin{array}{l}(3.47- \\
10.4)\end{array}$ & $(2.98-7.36)$ & $(2.58-6.86)$ & & & \\
\hline \multirow[t]{2}{*}{ PTX3 (ng/mL) } & 1.56 & 1.47 & 1.32 & 0.309 & 0.176 & 0.533 \\
\hline & $\begin{array}{l}(1.08- \\
2.43)\end{array}$ & $(0.96-2.08)$ & $(0.99-1.86)$ & & & \\
\hline \multirow{3}{*}{$\begin{array}{l}\text { GDF15 } \\
\text { (ng/mL) }\end{array}$} & 13.6 & 10.2 & 10.5 & $<0.001$ & $<0.001$ & 0.790 \\
\hline & $\begin{array}{l}(11.1- \\
18.3)\end{array}$ & $(7.56-13.7)$ & $(8.10-13.0)$ & & & \\
\hline & \multicolumn{3}{|c|}{ PTX3 $(+281 \mathrm{~A}>\mathrm{G})$ genotype } & \multicolumn{3}{|l|}{$p$ value } \\
\hline Biomarker & $\mathrm{AA}(n=72)$ & $\mathrm{GG}(n=91)$ & $\begin{array}{l}\text { AG }(n= \\
126)\end{array}$ & $\begin{array}{l}\text { AA vs. } \\
\text { GG }\end{array}$ & $\begin{array}{l}\text { AA vs. } \\
A G\end{array}$ & GG vs. $A G$ \\
\hline \multirow[t]{2}{*}{ hsCRP (mg/dL) } & 0.50 & 0.28 & 0.38 & $<0.001$ & 0.021 & 0.152 \\
\hline & $\begin{array}{l}(0.24- \\
1.25)\end{array}$ & $(0.13-0.63)$ & $(0.15-0.80)$ & & & \\
\hline \multirow[t]{2}{*}{ IL6 (pg/mL) } & 4.76 & 3.62 & 4.03 & 0.040 & 0.113 & 0.549 \\
\hline & $\begin{array}{l}(3.30- \\
8.66)\end{array}$ & $(2.61-6.94)$ & $(2.64-6.70)$ & & & \\
\hline \multirow[t]{2}{*}{ PTX3 (ng/mL) } & 1.28 & 1.41 & 1.47 & 0.987 & 0.430 & 0.424 \\
\hline & $\begin{array}{l}(1.02- \\
1.86)\end{array}$ & $(0.85-1.86)$ & $(0.98-2.26)$ & & & \\
\hline \multirow{2}{*}{$\begin{array}{l}\text { GDF15 } \\
\text { (ng/mL) }\end{array}$} & 10.4 & 11.4 & 10.2 & 0.146 & 0.767 & 0.081 \\
\hline & $\begin{array}{l}(7.98- \\
13.3)\end{array}$ & $(8.84-14.4)$ & $(7.67-13.5)$ & & & \\
\hline $\begin{array}{l}\text { Data is presente } \\
\text { performed by th } \\
\text { sensitivity C-rea }\end{array}$ & $\begin{array}{l}\text { Is median (ir } \\
\text { lann-Whitne }\end{array}$ & $\begin{array}{l}\text { rquartile rang } \\
\text { test. GDF15 }\end{array}$ & $\begin{array}{l}\text { Multiple cor } \\
\text { rowth differe }\end{array}$ & $\begin{array}{l}\text { arisons } k \\
\text { ation fac }\end{array}$ & $\begin{array}{l}\text { een genot } \\
5 \text {; hsCRP }\end{array}$ & $\begin{array}{l}\text { s were } \\
\text { h- }\end{array}$ \\
\hline
\end{tabular}


Regarding the PTX3 polymorphism, the AA genotype presented the highest values of hsCRP (significant for $A A$ versus $G G$ and $A A$ versus $A G$ ) and IL6 (significant for AA versus GG), while GG genotype presented the lowest values of both biomarkers. There were no significant differences in the levels of GDF15 and PTX3 between genotypes for this polymorphism.

We also evaluated the correlation between the different inflammatory markers on study, within each polymorphic genotype (Table 3). In all IL6 $(-174 \mathrm{G}>\mathrm{C})$ genotypes, hsCRP was positively and significantly correlated with IL6; hsCRP also showed significant positive correlations with PTX3 and GDF15 only for the GG genotype. The correlations between IL6 and PTX3, were positive for all genotypes, achieving significance only for GG genotype; considering IL6 and GDF15, the correlation was negative for CC genotype and positive for the other genotypes, reaching statistical significance only in CG genotype.

\section{Table 3}

Correlations between the inflammatory markers, within each IL6 and PTX3 polymorphic genotype, in endstage renal disease patients $(n=289)$

\begin{tabular}{|c|c|c|c|c|}
\hline IL6 $(-174 G>C)$ genotype & Biomarker vs. & IL6 (pg/mL) & PTX3 (ng/mL) & GDF15 (ng/mL) \\
\hline $\mathrm{CC}(n=28)$ & \multirow[t]{3}{*}{$\mathrm{hsCRP}(\mathrm{mg} / \mathrm{dL})$} & $0.472 *$ & 0.079 & -0.101 \\
\hline GG $(n=137)$ & & $0.525^{\star \star \star}$ & $0.187^{\star}$ & $0.187^{*}$ \\
\hline CG $(n=124)$ & & $0.597 * \star \star$ & 0.047 & 0.165 \\
\hline $\mathrm{CC}(n=28)$ & \multirow[t]{3}{*}{ IL6 (pg/mL) } & - & 0.195 & -0.203 \\
\hline GG $(n=137)$ & & - & $0.225^{\star \star}$ & 0.132 \\
\hline CG $(n=124)$ & & - & 0.082 & $0.250 * \star$ \\
\hline PTX3 $(+281 \mathrm{~A}>\mathrm{G})$ genotype & Biomarker vs. & IL6 (pg/mL) & PTX3 (ng/mL) & GDF15 $(\mathrm{ng} / \mathrm{mL})$ \\
\hline $\mathrm{AA}(n=72)$ & \multirow[t]{3}{*}{$\mathrm{hsCRP}(\mathrm{mg} / \mathrm{dL})$} & $0.582^{\star \star \star}$ & 0.038 & -0.217 \\
\hline $\mathrm{GG}(n=91)$ & & $0.576 * \star \star$ & 0.154 & 0.021 \\
\hline AG $(n=126)$ & & $0.546 * \star \star$ & 0.166 & $0.299 * \star$ \\
\hline $\mathrm{AA}(n=72)$ & \multirow[t]{3}{*}{ IL6 (pg/mL) } & - & 0.199 & 0.074 \\
\hline $\mathrm{GG}(n=91)$ & & - & 0.118 & -0.203 \\
\hline AG $(n=126)$ & & - & 0.066 & $0.274 * \star$ \\
\hline $\begin{array}{l}{ }^{*} p<0.05 ;{ }^{* *} p<0.01 ; * * \star \\
\text { genotypes (Spearman's rank } \\
\text { sensitivity C-reactive protein; }\end{array}$ & $\begin{array}{l}1 \text { correlations bet } \\
\text { rrelation } r) \text {. GDF1 } \\
\text { 5: interleukin 6; } P^{-}\end{array}$ & $\begin{array}{l}\text { een paramete } \\
\text { growth differ } \\
\text { «: pentraxin } 3\end{array}$ & $\begin{array}{l}\text { for each IL } 6 \text { or P } \\
\text { tiation factor } 15 \text {; }\end{array}$ & $\begin{array}{l}\text { X3 polymorphic } \\
\text { sCRP: high- }\end{array}$ \\
\hline
\end{tabular}

Concerning the PTX3 (+281A > G) polymorphism (Table 3), hsCRP and IL6 were positively and significantly correlated for all genotypes; no significant correlations were found between hsCRP and PTX3 for any genotype; hsCRP and GDF15 showed a negative correlation for AA genotype, while both GG and $A G$ alleles presented a positive correlation that achieved a statistical significance in the AG genotype. 
For all genotypes, no statistically significant associations were observed between IL6 and PTX3; a significant positive correlation was observed between IL6 and GDF15, for GG carriers and in the AG carriers we found a negative correlation, although without significance.

\section{IL6 and PTX3 genotype frequencies in deceased and alive ESRD patients (1-year follow-up)}

During the one-year follow-up of the ESRD patients, 21 of them left the study (transplanted, recovered renal function, transferred to another HD clinic or quit KRT). In the remaining ESRD patients $(n=268)$, a total of $28(10.4 \%)$ died due to several causes, including CVD, cachexia, infectious diseases, or other causes. The distribution of the allele frequencies of IL6 and PTX3 polymorphisms in deceased and alive ESRD patients is shown in Table 4.

Table 4

- Genotype frequencies in deceased and alive end-stage renal disease patients (1-year follow-up), according to IL6 (rs1800795) and PTX3 (rs2305619) polymorphisms

\begin{tabular}{|c|c|c|}
\hline IL6 (-174G > C) genotype & Deceased/Alive [n (\%)] & $p\left(x^{2}\right)$ \\
\hline $\mathrm{CC}$ & $6 / 21(22.2 / 77.8)$ & \multirow[t]{3}{*}{0.089} \\
\hline GG & 13/113 (10.3/89.7) & \\
\hline CG & 9/106 (7.8/92.2) & \\
\hline PTX3 $(+281 \mathrm{~A}>\mathrm{G})$ genotype & Deceased/Alive [ $n(\%)]$ & $p\left(\chi^{2}\right)$ \\
\hline AA & $7 / 61(10.3 / 89.7)$ & \multirow[t]{3}{*}{0.666} \\
\hline GG & $7 / 78(8.2 / 91.8)$ & \\
\hline AG & 14/101 (12.2/87.8) & \\
\hline
\end{tabular}

For IL6 rs1800795, the frequency of CC, GG and CG genotypes between deceased and alive ESRD patients showed a suggestive trend towards a higher prevalence of deceased patients with the CC genotype. Actually, homozygous CC individuals showed the highest mortality rate (22.2\%), followed by GG homozygous (10.3\%); the heterozygous individuals showed the best outcome regarding mortality (7.8\%). For individuals with the CC, GG, and CG genotype, the survival cumulative curves for IL6 polymorphism were 100 [54-138], 211 [83-290] and 291 [72-322] days, respectively; the $p$ values were 0.023 for CC versus GG, 0.157 for CC versus $C G$, and 0.570 for CG versus GG (Fig. 1A).

Considering the PTX3 polymorphism, the frequencies of AA, GG and AG genotypes were similar in both alive and deceased patients, and no significant differences were observed in mortality rates between the different genotypes (Table 4). For PTX3 polymorphism, the survival cumulative curves for individuals 
with AA, GG and AG genotypes were, respectively, 238 [129-333], 198 [73-294] and 118 [54-295] days. The $p$ values achieved were 0.338 for AA versus $G G, 0.332$ for AA versus $A G$ and 0.654 for GG versus AG (Fig. 1B).

\section{Mortality according to IL6 polymorphic genotypes and blood levels of inflammatory markers}

The blood levels of hsCRP, IL6, PTX3 and GDF15 in deceased and alive patients, according to the IL6 and PTX3 polymorphisms, are presented in Table 5. Considering the IL6 polymorphism, deceased patients with CC genotype showed higher hsCRP concentration when compared to GG (statistically significant) and heterozygous patients; moreover, deceased patients with CC genotype showed higher levels of PTX3 and similar values of GDF15 compared to GG and CG; deceased patients with GG genotype showed the highest levels of IL6. For GDF15, alive patients with CC genotype presented significantly higher concentrations, compared to the other genotypes. The alive patients presented lower levels of IL6 and PTX3 compared with deceased patients in all genotypes.

Considering the PTX3 polymorphism, deceased patients with AA genotype had the highest levels of hsCRP, IL6 and GDF15, followed by the heterozygous genotype; the GG genotype showed the lowest hsCRP levels; PTX3 levels for AA genotype were the highest among all three genotypes. Alive patients with GG and AG genotypes presented lower levels of hsCRP, IL6, PTX3 and GDF15, compared to deceased ones. 
Table 5

Blood levels of IL6, hsCRP, PTX3 and GDF15 according to the IL6 (rs1800795) and PTX3 (rs2305619) single nucleotide polymorphisms in alive and deceased end-stage renal disease patients

\begin{tabular}{|c|c|c|c|c|c|c|}
\hline \multirow{2}{*}{$\begin{array}{l}\text { IL6 }(-174 G>C) \\
\text { polymorphism }\end{array}$} & \multicolumn{2}{|c|}{$\begin{array}{l}\text { CC genotype } \\
(n=27)\end{array}$} & \multicolumn{2}{|c|}{$\begin{array}{l}\text { GG genotype } \\
(n=126)\end{array}$} & \multicolumn{2}{|c|}{$\begin{array}{l}\text { CG genotype } \\
(n=115)\end{array}$} \\
\hline & $\begin{array}{l}\text { Alive } \\
(n=21)\end{array}$ & $\begin{array}{l}\text { Deceased } \\
(n=6)\end{array}$ & $\begin{array}{l}\text { Alive } \\
(n=113)\end{array}$ & $\begin{array}{l}\text { Deceased } \\
(n=13)\end{array}$ & $\begin{array}{l}\text { Alive } \\
(n= \\
106)\end{array}$ & $\begin{array}{l}\text { Deceased } \\
(n=9)\end{array}$ \\
\hline hsCRP & 0.39 & $1.28 *$ & 0.45 & 0.37 & 0.25 & 0.63 \\
\hline$(\mathrm{mg} / \mathrm{dL})$ & $\begin{array}{l}(0.29- \\
0.80)\end{array}$ & $\begin{array}{l}(0.55- \\
3.64)\end{array}$ & $\begin{array}{l}(0.16- \\
0.82)\end{array}$ & $\begin{array}{l}(0.29- \\
1.10)\end{array}$ & $\begin{array}{l}(0.13- \\
0.68)\end{array}$ & $\begin{array}{l}(0.14- \\
1.64)\end{array}$ \\
\hline IL6 & 4.01 & 6.26 & 3.90 & $8.84^{\star \star}$ & 3.43 & $5.73^{\star}$ \\
\hline$(\mathrm{pg} / \mathrm{mL})$ & $\begin{array}{l}(3.06- \\
10.9)\end{array}$ & $\begin{array}{l}(3.62- \\
22.4)\end{array}$ & $\begin{array}{l}(2.78- \\
7.06)\end{array}$ & $\begin{array}{l}(4.48 \\
-15.0)\end{array}$ & $\begin{array}{l}(2.54- \\
6.72)\end{array}$ & $\begin{array}{l}(3.77- \\
11.6)\end{array}$ \\
\hline РTX3 & 1.41 & 2.18 & 1.28 & $1.96 *$ & 1.33 & 2.13 \\
\hline$(\mathrm{ng} / \mathrm{mL})$ & $\begin{array}{l}(1.04- \\
2.26)\end{array}$ & $\begin{array}{l}(1.53- \\
5.72)\end{array}$ & $\begin{array}{l}(0.92- \\
1.90)\end{array}$ & $\begin{array}{l}(1.61- \\
2.20)\end{array}$ & $\begin{array}{l}(1.02- \\
1.84)\end{array}$ & $\begin{array}{l}(0.84- \\
3.18)\end{array}$ \\
\hline GDF15 & 14.0 & 11.6 & 10.3 & 10.2 & 10.5 & 11.4 \\
\hline$(\mathrm{ng} / \mathrm{mL})$ & $\begin{array}{l}(12.0- \\
18.2)\end{array}$ & $\begin{array}{l}(8.19- \\
34.6)\end{array}$ & $\begin{array}{l}(7.66- \\
13.7)\end{array}$ & $\begin{array}{l}(7.26- \\
13.3)\end{array}$ & $\begin{array}{l}(8.28- \\
13.1)\end{array}$ & $\begin{array}{l}(8.56- \\
13.2)\end{array}$ \\
\hline $\begin{array}{l}\text { PTX3 }(+281 \mathrm{~A}>\mathrm{G}) \\
\text { polymorphism }\end{array}$ & \multicolumn{2}{|c|}{$\begin{array}{l}\text { AA genotype } \\
(n=68)\end{array}$} & \multicolumn{2}{|c|}{$\begin{array}{l}\text { GG genotype } \\
(n=85)\end{array}$} & \multicolumn{2}{|c|}{$\begin{array}{l}\text { AG genotype } \\
(n=115)\end{array}$} \\
\hline 1-year Outcome & $\begin{array}{l}\text { Alive } \\
(n=61)\end{array}$ & $\begin{array}{l}\text { Deceased } \\
(n=7)\end{array}$ & $\begin{array}{l}\text { Alive } \\
(n=78)\end{array}$ & $\begin{array}{l}\text { Deceased } \\
(n=7)\end{array}$ & $\begin{array}{l}\text { Alive } \\
(n= \\
101)\end{array}$ & $\begin{array}{l}\text { Deceased } \\
(n=14)\end{array}$ \\
\hline hsCRP & 0.50 & 0.98 & 0.27 & 0.50 & 0.35 & 0.70 \\
\hline$(\mathrm{mg} / \mathrm{dL})$ & $\begin{array}{l}(0.22- \\
1.16)\end{array}$ & $\begin{array}{l}(0.33- \\
3.98)\end{array}$ & $\begin{array}{l}(0.13- \\
0.60)\end{array}$ & $\begin{array}{l}(0.28- \\
1.14)\end{array}$ & $\begin{array}{l}(0.13- \\
0.76)\end{array}$ & $\begin{array}{l}(0.15- \\
1.17)\end{array}$ \\
\hline IL6 & 4.57 & $14.3^{\star \star \star}$ & 3.61 & 4.45 & 3.48 & $5.60 *$ \\
\hline$(\mathrm{pg} / \mathrm{mL})$ & $\begin{array}{l}(3.26- \\
7.50)\end{array}$ & $\begin{array}{l}(11.3- \\
22.0)\end{array}$ & $\begin{array}{l}(2.53- \\
7.02)\end{array}$ & $\begin{array}{l}(3.87- \\
8.05)\end{array}$ & $\begin{array}{l}(2.58- \\
6.18)\end{array}$ & $\begin{array}{l}(3.74- \\
8.87)\end{array}$ \\
\hline
\end{tabular}

Data is presented as median (interquartile range). Multiple comparisons between genotypes were performed by the Mann-Whitney U test. ${ }^{*} p<0.050 .{ }^{*} p<0.01$ alive versus deceased. GDF15: growth differentiation factor 15; hsCRP: high-sensitivity C-reactive protein; IL6: interleukin 6; PTX3: pentraxin 3 


\begin{tabular}{|c|c|c|c|c|c|c|}
\hline \multirow{2}{*}{$\begin{array}{l}\text { IL6 (-174G > C) } \\
\text { polymorphism } \\
\text { PTX3 }\end{array}$} & \multicolumn{2}{|c|}{$\begin{array}{l}\text { CC genotype } \\
(n=27)\end{array}$} & \multicolumn{2}{|c|}{$\begin{array}{l}\text { GG genotype } \\
(n=126)\end{array}$} & \multicolumn{2}{|c|}{$\begin{array}{l}\text { CG genotype } \\
(n=115)\end{array}$} \\
\hline & 1.26 & 1.71 & 1.32 & $2.23^{\star}$ & 1.41 & $2.06 *$ \\
\hline$(\mathrm{ng} / \mathrm{mL})$ & $\begin{array}{l}(1.00- \\
1.85)\end{array}$ & $\begin{array}{l}(1.31- \\
2.18)\end{array}$ & $\begin{array}{l}(0.92- \\
1.80)\end{array}$ & $\begin{array}{l}(1.73- \\
7.18)\end{array}$ & $\begin{array}{l}(0.97- \\
2.24)\end{array}$ & $\begin{array}{l}(1.50- \\
2.86)\end{array}$ \\
\hline GDF15 & 10.8 & 11.7 & 10.5 & 10.2 & 10.1 & 11.0 \\
\hline (ng/mL) & $\begin{array}{l}(7.92- \\
13.5)\end{array}$ & $\begin{array}{l}(8.50- \\
14.2)\end{array}$ & $\begin{array}{l}(8.28- \\
13.1)\end{array}$ & $\begin{array}{l}(4.89- \\
14.5)\end{array}$ & $\begin{array}{l}(7.64- \\
13.6)\end{array}$ & $\begin{array}{l}(8.64- \\
13.6)\end{array}$ \\
\hline
\end{tabular}

The Cox regression survival analysis for all-cause mortality in $\operatorname{ESRD~}(n=268)$, using as reference the heterozygous patients for IL6 polymorphism (Table 6, unadjusted model), showed that CC patients presented a significantly higher mortality risk with a HR of 3.275 [1.165 to 9.204]. In the model adjusted for age, dialysis vintage and type of vascular access, the CC genotype continued to show a significantly higher risk for mortality than the heterozygotes, with a HR of 2.961; when adjusted for the comorbidities, diabetes mellitus and history of CVD, besides all the previous confounding factors, the HR increased to 3.356. The Cox regression analysis was not performed for PTX3 polymorphism since we have already shown that no differences existed between genotypes in terms of mortality rate (Table 4) or survival cumulative curves (Fig. 1B).

Table 6

Cox regression analysis according to the IL6 (rs1800795) polymorphism for all-cause mortality in endstage renal disease patients $(n=268)$

\begin{tabular}{|c|c|c|c|c|c|c|c|c|c|}
\hline \multirow{2}{*}{$\begin{array}{l}\text { Cox } \\
\text { Regression* } \\
\text { IL6 (-174G > } \\
\text { C) genotype }\end{array}$} & \multicolumn{3}{|c|}{ Unadjusted model } & \multicolumn{3}{|c|}{ Adjusted model ${ }^{1}$} & \multicolumn{3}{|c|}{ Adjusted mode ${ }^{2}$} \\
\hline & $p$ & $\mathrm{HR}$ & $\begin{array}{l}95.0 \% \\
\mathrm{Cl}\end{array}$ & $p$ & $\mathrm{HR}$ & $\begin{array}{l}95.0 \% \\
\mathrm{Cl}\end{array}$ & $p$ & $\mathrm{HR}$ & $\begin{array}{l}95.0 \% \\
\mathrm{Cl}\end{array}$ \\
\hline & & & for HR & & & for HR & & & for HR \\
\hline $\mathrm{CC}$ & 0.024 & 3.275 & $\begin{array}{l}1.165- \\
9.204\end{array}$ & 0.042 & 2.961 & $\begin{array}{l}1.040- \\
8.429\end{array}$ & 0.022 & 3.356 & $\begin{array}{l}1.188- \\
9.484\end{array}$ \\
\hline GG & 0.490 & 1.349 & $\begin{array}{l}0.577- \\
3.157\end{array}$ & 0.498 & 1.342 & $\begin{array}{l}0.573- \\
3.140\end{array}$ & 0.498 & 1.342 & $\begin{array}{l}0.573- \\
3.145\end{array}$ \\
\hline CG & 0.072 & - & - & 0.119 & - & - & 0.065 & - & - \\
\hline
\end{tabular}




\section{Discussion}

The identification and analysis of polymorphisms in genes that encode biochemical markers that are altered in CKD patients is important, since they might affect the outcome of the patients 1,21,22. The inflammatory biomarkers IL6 and PTX3 are particularly enhanced in ESRD patients and have been associated with a higher risk for CVD events, the major cause of death in these patients; still, how the polymorphisms of their encoding genes affect the inflammatory response and patient's outcome, remains poorly clarified. It is important to identify and validate common genetic variants and genotypes, to know if and how they influence patients' outcome; this knowledge may provide more adequate interventions in patients at higher risk. This study analyzed the allelic frequencies of two polymorphisms, namely IL6 $(-174 G>C)$ and PTX3 (+281A $>G)$, in ESRD patients and in controls; evaluated their association with the degree of inflammation, shown by the blood levels of IL6, PTX3, CRP and GDF15, and with mortality risk, by recording events of death along one year.

For IL6 rs 1800795, the frequency of CC, GG and CG genotypes for patients and controls was similar (9.7\%, 47.4\% and $42.9 \%$, in ESRD patients; $9.4 \%, 53.1 \%$ and $37.5 \%$, in controls) (Table 1 ). A study in a healthy Polish population, reported that the frequencies of IL6 $(-174 \mathrm{G} / \mathrm{C})$ genotype were $21.9 \%$ for CC, $28.8 \%$, for $G G$ and $49.3 \%$ for $C G$, which were similar to those described for German and British populations; however the frequencies reported for Italian and American Caucasians, American Blacks and Asian Americans are similar to those observed in our study groups ${ }^{38}$, in which GG is the most common genotype and $\mathrm{CC}$ genotype the less frequent ${ }^{39}$. We found an allelic frequency of 0.28 and 0.31 for allele $\mathrm{C}$ and 0.72 and 0.69 for allele $\mathrm{G}$, in controls and ESRD patients, respectively. According to the Reference SNP (rs) Report database for rs 1800795 , assessed on February, 25th 2021

(www.ncbi.nlm.nih.gov/snp/rs1800795), these frequencies are $0.44 / 0.56$ for alleles $\mathrm{C} / \mathrm{G}$ in the European population; the allelic frequencies in our studied population are closer to those reported for southern European ${ }^{40}$ and North-American populations ${ }^{41}$.

For PTX3 rs2305619, the genotype distribution was also similar between patients and controls $(24.9 \%$, $31.5 \%$ and $43.6 \%$ for AA, GG and AG, respectively, in ESRD patients; $15.6 \%, 31.3 \%$ and $53.2 \%$, respectively, for controls). A study in healthy European subjects, reported that the distribution of AA, GG and AG genotypes was, respectively, $22.94 \%, 27.12 \%$ and $49.94 \%{ }^{33}$. Another study involving Taiwanese controls showed $12.2 \%, 41.5 \%$ and $46.3 \%$, for AA, GG and AG genotypes, respectively ${ }^{34}$. Our controls and ESRD patients presented similar genotype frequencies to those reported by Barbati et al. ${ }^{33}$. We also found that the allelic frequencies were 0.42 and 0.46 for allele $A$, and 0.58 and 0.54 for allele $G$, in controls and ESRD patients, respectively, which is in accordance with data obtained from Reference SNP (rs) Report database for rs2305619, assessed on February, 25th 2021 (www.ncbi.nlm.nih.gov/snp/rs2305619), for a European population (allele A: 0.48 and allele G: 0.52). Thus, the allelic frequencies for IL6 and PTX3 polymorphisms in our patient cohort were similar to those described in other European populations. Moreover, as the genotype distribution between controls and ESRD patients (Table 1) was similar, it seems that none of the different alleles were more prevalent in ESRD patients. Additionally, both IL6 and 
PTX3 polymorphisms genotype frequencies did not differ in ESRD patients, when sub-analyzed according to gender, etiology of CKD, type of vascular access for dialysis procedure, dialysis vintage, dialysis type, diabetes, hypertension and CVD history.

In our cohort of ESRD patients, IL6 $(-174 \mathrm{G}>\mathrm{C})$ polymorphic genotypes showed that the GG and CC genotypes were associated with higher circulating levels of IL6, although without reaching statistical significance (Table 2). Actually, data on literature about the effect of IL6 $(-174 \mathrm{G}>\mathrm{C})$ polymorphic genotypes on IL6 circulating levels is still controversial.

In a study with Indian ESRD patients with malnutrition inflammation complex syndrome, the $\mathrm{C}$ allele was associated with higher IL6 levels, and both CC and CG genotypes conferred a higher (about 3-fold) mortality risk than the GG genotype; moreover, the increased levels of IL6, when associated with higher TNF- $\alpha$ and low IL-10 levels, appeared to contribute for the activation of inflammatory pathways that lead to higher disease susceptibility, poorer nutritional status and lower survival rate ${ }^{25}$. Another study, in a Southern Italian CKD cohort, also showed that patients with the CC genotype presented higher circulating levels of IL 6 than those with CG or GG genotypes. Furthermore, CKD patients with CC genotype and high levels of IL6 showed a higher incidence rate (87\%) of cardiovascular events, when compared to those with the $\mathrm{CG}$ or GG genotypes ${ }^{28}$. In contrast, some studies in patients with other inflammatory clinical conditions, have suggested that the homozygous genotype for $\mathrm{C}$ allele confers protection, as it was associated with lower IL 6 circulating levels ${ }^{42-46}$. In a study in Korean patients on HD, the $C$ allele of the IL6 (-174 G/C) was not detected, and this absence did not seem to interfere in IL6 circulating levels, in spite of the high circulating levels of IL6 (about three times higher than those found in our studied patients) ${ }^{26}$. Different results were obtained in a study of Caucasian and African American ESRD patients on long-term dialysis, which showed the association of GG and CG genotypes with higher levels of IL6, as compared with those with the CC genotype ${ }^{39}$.

Concerning the effect of IL6 $(-174 \mathrm{G}>\mathrm{C})$ polymorphic genotypes on the other studied inflammatory biomarkers, we found that ESRD patients with CC genotype showed higher CRP levels (median: 0.52 $\mathrm{mg} / \mathrm{L}$ ), when compared to $\mathrm{CG}$ and $\mathrm{GG}$ genotypes (median: $0.42 \mathrm{mg} / \mathrm{L}$ and $0.30 \mathrm{mg} / \mathrm{L}$, respectively), reaching statistical significance for CC versus CG (Table 2). Higher CRP values were also reported in CKD patients with CC genotype, compared with $C G$ and GG genotypes, in other studies ${ }^{28}$. Comparing PTX3 and GDF15 levels between IL6 polymorphic genotypes, we found that the CC genotype presented the highest median levels for both markers, reaching the increase in GDF15 a statistical significance. Thus, our data suggest that the CC genotype for IL6 $(-174 G>C)$ polymorphism contributes to an increased inflammatory response, by increasing CRP, PTX3 and GDF15 circulating levels in ESRD on dialysis.

Higher GDF15 concentrations have been associated with mortality and with heart failure events ${ }^{47}$, as well as with CKD progression ${ }^{48}$. Also, there is evidence that CRP stimulates GDF15 expression in endothelial cells ${ }^{8,49}$. As already referred, our data show that in ESRD patients the CC genotype is associated to significantly increased GDF15 levels and a trend for higher IL6/CRP levels (Table 2); 
however, we found negative correlations between GDF15 and IL6/CRP for CC genotype patients, while for the other variants these correlations were positive (Table 3 ). This suggests that alternate transcription of IL6 gene might lead to the activation of different metabolic pathways, which could have a direct impact on GDF15 circulating levels.

The highest levels of hsCRP, PTX3 and GDF15 that we found in ESRD patients with the CC genotype, suggest that this genotype may increase the risk for CVD and for a poor outcome in ESRD patients. Epidemiologic studies have shown elevated levels of the inflammatory biomarkers, CRP, PTX3, and IL6 and GDF15 5,6,47 in ESRD patients, and their association with the risk for CVD events and mortality $12,28,47,48,50,51$. Considering that the genotypic variations do not change over time, this highlights the importance of variants that although less frequent, may have biological value ${ }^{51}$.

The evaluation of PTX3 levels has been proposed as an important sensitive tool to predict cardiovascular mortality risk in patients with advanced CKD, increasing before traditional systemic inflammation markers, such as CRP, commonly used in laboratorial/clinical practice ${ }^{5,52}$. In our ESRD patient cohort, for the PTX3 polymorphism, a trend towards higher circulating PTX3 levels was found in the AG genotype, compared to the others. However, AA genotype presented the highest values of hsCRP and IL6, and GG genotype the lowest values (Table 2). As far as we know, no studies about the effect of this polymorphism have been performed in ESRD patients. Studies in patients at risk for myocardial infarction reported that this PTX3 polymorphism is associated with higher plasma PTX3 levels in individuals with AA genotype of rs $2305619^{33}$. Actually, several studies have proposed PTX3 as an inflammatory biomarker associated with inflammation and CVD, and as an early marker of CV mortality in ESRD patients ${ }^{5,52}$. Moreover, elevated PTX3 levels have been also associated with lower eGFR and appear to independently predict incident CKD in the elderly, and, thus, appears to be a promising biomarker of kidney disease ${ }^{15}$. Our data show that the AA genotype, not only presents the highest levels of hsCRP and IL6, but also presents a positive significant correlation between them (Table 3), suggesting a higher risk for a poorer outcome.

As referred, along one year we monitored patients, registering the events of death, in order to evaluate how the IL6 and PTX3 polymorphisms could affect their outcome. Along the one-year follow-up, 21 patients dropped from the study (e.g. transplant, recovering, abandoning KRT) and 28 patients died, showing a mortality rate of $10.4 \%$ ( 28 out of 268 ).

Evaluating mortality according to the PTX3 $(+281 \mathrm{~A}>\mathrm{G})$ polymorphism, we found that the genotype frequency between deceased and alive patients did not differ and the mortality rates were similar between genotypes (AA: 10.3\%; GG: 8.2\%; AG: 12.2\%) (Table 4). Considering the IL6 (-174G >C) polymorphism, the genotype distribution in deceased patients was different from that observed for survivors, almost reaching statistical significance $(p=0.089)$; the mortality rates per genotype were $22.2 \%$ for CC genotype, $10.3 \%$ for $G G$ and $7.8 \%$ for $C G$ (Table 4). The survival cumulative curves (Fig. $1 \mathrm{~A}$ ) are also strongly suggestive of a poorer outcome for patients with the CC genotype; actually, the mortality rate in CC genotype carriers was more than 2-fold of that observed in the other two genotypes, which 
presented similar mortality rates, although a trend towards a lower value was observed in heterozygous individuals.

When comparing the circulating levels of the inflammatory markers in deceased and alive patients, we found that deceased patients with the CC genotype presented increased hsCRP (more than 3-fold), IL6 and PTX3 (both 1.5-fold) and decreased GDF15 levels. In the other two genotypes, the increase in hsCRP was lower for deceased patients, suggesting an enhancement in inflammation for CC genotype, and a less favorable outcome for their carriers (Table 5).

Curiously, the levels of GDF15 for alive patients with CC genotype, were significantly increased, when compared to the other two genotypes (Table 5). Considering that this genotype appears to be the less favorable (Table 4), we wonder about the importance of the influence of the IL6 $(-174 \mathrm{G}>\mathrm{C})$

polymorphism on GDF15 levels, which most certainly deserves further investigation. Moreover, the crosssurvival analysis (Cox regression) further suggests that the IL6 polymorphic CC genotype is associated with a higher mortality risk (approximately 3-fold higher than in CG genotype), and heterozygosity with the lowest mortality risk (Table 6 and Fig. 1A). Performing Cox regression analysis and adjusting for confounding factors, such as age, dialysis vintage, type of vascular access, diabetes and history of CVD, the CC genotype remained as an independent predictor of death (Table 6, adjusted models). Our data suggest that ESRD patients with CC genotype have almost three-fold higher risk for a poorer outcome, and the heterozygous, the most favorable outcome. In line with our findings, a meta-analysis of 74 studies with 86,229 subjects, evaluated the association of -174 G > C IL6 (rs1800795) with the risk for CVD, and found that the $C$ allele was associated with a higher risk for CVD ${ }^{6,29}$.

When comparing the circulating levels of the inflammatory markers in deceased and alive patients, according to the PTX3 polymorphic genotypes, we found that deceased patients with the AA genotype presented the highest increase in IL6 (almost 3-fold than the survivors); the increase in the values of the other inflammatory markers in deceased patients were similar between genotypes. The mortality rates and survival cumulative curves for PTX3 polymorphism, were similar in all genotypes (Fig. 1B). Thus, in spite of the enhancement in the inflammatory markers, hsCRP and IL6 observed in AA genotype carriers and the striking increase in IL6 for AA genotype, in deceased patients, we did not find a significant impact of the PTX3 polymorphism in the outcome of these patients.

\section{Conclusions}

Our data show that both IL6 $(-174 \mathrm{G}>\mathrm{C})(\mathrm{r} 1800795)$ and PTX3 $(+281 \mathrm{~A}>\mathrm{G})(\mathrm{rs} 2305619)$ polymorphisms seem to modulate the inflammatory response in ESRD patients. The CC genotype, the less frequent genotype for IL6 polymorphism, appears to enhance the inflammatory response in ESRD patients, aggravating the patients' outcome. Our study suggests that inflammation can be induced by underlying individual genetic characteristics and highlights the importance of research on variants that, although less frequent, may have biological value, as it appears to be the case of CC genotype for IL6 polymorphism. 


\section{Declarations}

\section{Acknowledgments}

The authors thank all the institutions that participated in this work. We grateful to Dr. Laura Pereira and Miss Ana Paula Ribeiro for the technical assistance. This work was supported by the Applied Molecular Biosciences Unit - UCIBIO which is financed by national funds from FCT(UIDP/04378/2020 and UIDB/04378/2020), by North Portugal Regional Coordination and Development Commission (CCDRN)/NORTE2020/Portugal 2020 (Norte-01-0145-FEDER-000024) and by REQUIMTE-Rede de Química e Tecnologia-Associação in the form of a researcher [(S. Rocha - project Dial4Life co-financed by FCT/MCTES (PTDC/MEC-CAR/31322/2017) and FEDER/COMPETE 2020 (POCI-01-0145-FEDER031322)].

\section{Conflict of interest}

The authors declare no conflict of interest, financial, or otherwise.

\section{References}

1. Corredor, Z. et al. Genetic Variants Associated with Chronic Kidney Disease in a Spanish Population. Sci Rep. 10, 144 https://doi.org/10.1038/s41598-019-56695-2 (2020).

2. Levey, A. S. et al. The definition, classification, and prognosis of chronic kidney disease: a KDIGO Controversies Conference report. Kidney Int 80, 17-28, doi:10.1038/ki.2010.483 (2011).

3. Welfare, A. I. o. H. a. Projections of the prevalence of treated end-stage kidney disease in Australia, 2012-2020. Cat. no. PHE 176. Canberra: AlHW.,1-51(2014).

4. Liyanage, T. et al. Worldwide access to treatment for end-stage kidney disease: a systematic review. Lancet. 385, 1975-1982 https://doi.org/10.1016/S0140-6736(14)61601-9 (2015).

5. Valente, M. J. et al. Long Pentraxin 3 as a Broader Biomarker for Multiple Risk Factors in End-Stage Renal Disease: Association with All-Cause Mortality. Mediators Inflamm 2019, 3295725, doi:10.1155/2019/3295725 (2019).

6. Dai, L., Golembiewska, E., Lindholm, B. \& Stenvinkel, P. End-Stage Renal Disease, Inflammation and Cardiovascular Outcomes. Contrib Nephrol. 191, 32-43 https://doi.org/10.1159/000479254 (2017).

7. Ho, J. E. et al. Biomarkers of cardiovascular stress and incident chronic kidney disease. Clin Chem. 59, 1613-1620 https://doi.org/10.1373/clinchem.2013.205716 (2013).

8. Kim, J. S., Kim, S., Won, C. W. \& Jeong, K. H. Association between Plasma Levels of Growth Differentiation Factor-15 and Renal Function in the Elderly: Korean Frailty and Aging Cohort Study. Kidney Blood Press Res. 44, 405-414 https://doi.org/10.1159/000498959 (2019).

9. Tanno, T., Noel, P. \& Miller, J. L. Growth differentiation factor 15 in erythroid health and disease. Curr Opin Hematol. 17, 184-190 https://doi.org/10.1097/MOH.0b013e328337b52f (2010). 
10. Lukaszyk, E., Lukaszyk, M., Koc-Zorawska, E., Bodzenta-Lukaszyk, A. \& Malyszko, J. GDF-15, iron, and inflammation in early chronic kidney disease among elderly patients. Int Urol Nephrol. 48, 839844 https://doi.org/10.1007/s11255-016-1278-z (2016).

11. Rohatgi, A. et al. Association of growth differentiation factor-15 with coronary atherosclerosis and mortality in a young, multiethnic population: observations from the Dallas Heart Study. Clin Chem. 58, 172-182 https://doi.org/10.1373/clinchem.2011.171926 (2012).

12. Wang, K. et al. Cardiac Biomarkers and Risk of Mortality in CKD (the CRIC Study). Kidney Int Rep. 5, 2002-2012 https://doi.org/10.1016/j.ekir.2020.08.028 (2020).

13. Tong, M. et al. Plasma pentraxin 3 in patients with chronic kidney disease: associations with renal function, protein-energy wasting, cardiovascular disease, and mortality. Clin J Am Soc Nephrol. 2, 889-897 https://doi.org/10.2215/CJN.00870207 (2007).

14. Speeckaert, M. M., Speeckaert, R., Carrero, J. J., Vanholder, R. \& Delanghe, J. R. Biology of human pentraxin 3 (PTX3) in acute and chronic kidney disease. J Clin Immunol. 33, 881-890 https://doi.org/10.1007/s10875-013-9879-0 (2013).

15. Sjoberg, B. et al. Association between levels of pentraxin 3 and incidence of chronic kidney disease in the elderly. J Intern Med. 279, 173-179 https://doi.org/10.1111/joim.12411 (2016).

16. Casula, M. et al. Update on the role of Pentraxin 3 in atherosclerosis and cardiovascular diseases. Vascul Pharmacol. 99, 1-12 https://doi.org/10.1016/j.vph.2017.10.003 (2017).

17. Su, H., Lei, C. T. \& Zhang, C. Interleukin-6 Signaling Pathway and Its Role in Kidney Disease: An Update. Frontiers in Immunology8, doi:ARTN 405 3389/fimmu.2017.00405 (2017).

18. Kaminska, J. et al. IL 6 but not TNF is linked to coronary artery calcification in patients with chronic kidney disease. Cytokine. 120, 9-14 https://doi.org/10.1016/j.cyto.2019.04.002 (2019).

19. Lousa, I. et al. New Potential Biomarkers for Chronic Kidney Disease Management-A Review of the Literature. Int J Mol Sci. 22, https://doi.org/10.3390/ijms22010043 (2020).

20. Sun, J. et al. Biomarkers of Cardiovascular Disease and Mortality Risk in Patients with Advanced CKD. Clin J Am Soc Nephrol. 11, 1163-1172 https://doi.org/10.2215/CJN.10441015 (2016).

21. Kottgen, A. et al. Multiple loci associated with indices of renal function and chronic kidney disease. Nat Genet. 41, 712-717 https://doi.org/10.1038/ng.377 (2009).

22. Okada, R. et al. Pro-/anti-inflammatory cytokine gene polymorphisms and chronic kidney disease: a cross-sectional study. BMC Nephrol. 13, 2 https://doi.org/10.1186/1471-2369-13-2 (2012).

23. Rao, M. et al. Cytokine gene polymorphism and progression of renal and cardiovascular diseases. Kidney Int. 72, 549-556 https://doi.org/10.1038/sj.ki.5002391 (2007).

24. Al-Radeef, M. Y., Allawi, A. A. D. \& Fawzi, H. A. Interleukin-6 gene polymorphisms and serum erythropoietin and hemoglobin in hemodialysis Iraqi patients. Saudi J Kidney Dis Transpl. 29, 10421049 https://doi.org/10.4103/1319-2442.243952 (2018).

25. Sharma, R., Agrawal, S., Saxena, A. \& Sharma, R. K. Association of IL-6, IL-10, and TNF-alpha gene polymorphism with malnutrition inflammation syndrome and survival among end stage renal 
disease patients. J Interferon Cytokine Res. 33, 384-391 https://doi.org/10.1089/jir.2012.0109 (2013).

26. Ryu, J. H. \& Kim, S. J. Interleukin-6 -634 C/G and - 174 G/C polymorphisms in Korean patients undergoing hemodialysis. Korean J Intern Med. 27, 327-337 https://doi.org/10.3904/kjim.2012.27.3.327 (2012).

27. Neelofar, K., Ahmad, J., Ahmad, A. \& Alam, K. Study of IL4-590C/T and IL6-174G/C Gene Polymorphisms in Type 2 Diabetic Patients With Chronic Kidney Disease in North Indian Population. J Cell Biochem. 118, 1803-1809 https://doi.org/10.1002/jcb.25853 (2017).

28. Spoto, B. et al. Association of IL- 6 and a functional polymorphism in the IL- 6 gene with cardiovascular events in patients with CKD. Clin J Am Soc Nephrol. 10, 232-240 https://doi.org/10.2215/CJN.07000714 (2015).

29. Gonzalez-Castro, T. B. et al. Interleukin 6 (rs1800795) gene polymorphism is associated with cardiovascular diseases: a meta-analysis of 74 studies with 86,229 subjects. EXCL/ J. 18, 331-355 https://doi.org/10.17179/excli2019-1248 (2019).

30. Hassan, M. O. et al. Interleukin-6 gene polymorhisms and interleukin-6 levels are associated with atherosclerosis in CKD patients. Clin Nephrol. https://doi.org/10.5414/CNP92S114 (2019).

31. Introna, M. et al. Cloning of mouse $\mathrm{ptx} 3$, a new member of the pentraxin gene family expressed at extrahepatic sites. Blood. 87, 1862-1872 (1996).

32. Bottazzi, B. et al. Multimer formation and ligand recognition by the long pentraxin PTX3. Similarities and differences with the short pentraxins C-reactive protein and serum amyloid P component. $J$ Biol Chem. 272, 32817-32823 https://doi.org/10.1074/jbc.272.52.32817 (1997).

33. Barbati, E. et al. Influence of pentraxin 3 (PTX3) genetic variants on myocardial infarction risk and PTX3 plasma levels. PLoS One. 7, e53030 https://doi.org/10.1371/journal.pone.0053030 (2012).

34. Yeh, C. M. et al. Functional Genetic Variant of Long Pentraxin 3 Gene Is Associated With Clinical Aspects of Oral Cancer in Male Patients. Front Oncol. 9, 581 https://doi.org/10.3389/fonc.2019.00581 (2019).

35. Zhu, H. et al. Association of Pentraxin 3 Gene Polymorphisms with Susceptibility to Diabetic Nephropathy. Med Sci Monit. 23, 428-436 https://doi.org/10.12659/msm.902783 (2017).

36. Badr, E. A., Hamoda, G. E., Tayel, S. I. \& Elshayeb, E. I. Association of genetic variants of pentraxin 3 rs3816527 with hypertension in Chronic kidney disease patients. Mol Cell Biochem. 425, 203-212 https://doi.org/10.1007/s11010-016-2874-z (2017).

37. Zandifar, A., Iraji, N., Taheriun, M., Tajaddini, M. \& Javanmard, S. H. Association of the long pentraxin PTX3 gene polymorphism (rs3816527) with migraine in an Iranian population. J Neurol Sci. 349, 185-189 https://doi.org/10.1016/j.jns.2015.01.015 (2015).

38. Kurzawski, M. et al. Frequencies of the common promoter polymorphisms in cytokine genes in a Polish population. Int J Immunogenet. 32, 285-291 https://doi.org/10.1111/j.1744313X.2005.00524.x (2005). 
39. Balakrishnan, V. S. et al. Cytokine gene polymorphisms in hemodialysis patients: association with comorbidity, functionality, and serum albumin. Kidney Int. 65, 1449-1460 https://doi.org/10.1111/j.1523-1755.2004.00531.x (2004).

40. Poli, F. et al. Allele frequencies of polymorphisms of TNFA, IL-6, IL-10 and IFNG in an Italian Caucasian population. Eur J Immunogenet. 29, 237-240 https://doi.org/10.1046/j.13652370.2002.00303.x (2002).

41. Hoffmann, S. C. et al. Ethnicity greatly influences cytokine gene polymorphism distribution. Am J Transplant. 2, 560-567 https://doi.org/10.1034/j.1600-6143.2002.20611.x (2002).

42. Fishman, D. et al. The effect of novel polymorphisms in the interleukin-6 (IL-6) gene on IL-6 transcription and plasma IL- 6 levels, and an association with systemic-onset juvenile chronic arthritis. J Clin Invest. 102, 1369-1376 https://doi.org/10.1172/JCl2629 (1998).

43. Hulkkonen, J., Pertovaara, M., Antonen, J., Pasternack, A. \& Hurme, M. Elevated interleukin-6 plasma levels are regulated by the promoter region polymorphism of the IL6 gene in primary Sjogren's syndrome and correlate with the clinical manifestations of the disease. Rheumatology (Oxford). 40, 656-661 https://doi.org/10.1093/rheumatology/40.6.656 (2001).

44. Libra, M. et al. Analysis of G(-174)C IL-6 polymorphism and plasma concentrations of inflammatory markers in patients with type 2 diabetes and peripheral arterial disease. J Clin Pathol. 59, 211-215 https://doi.org/10.1136/jcp.2004.025452 (2006).

45. Lim, C. S. et al. The $-174 \mathrm{G}$ to $\mathrm{C}$ polymorphism of interleukin-6 gene is very rare in Koreans. Cytokine. 19, 52-54 https://doi.org/10.1006/cyto.2002.1951 (2002).

46. Pramudji, H., Demes, C. M., Dewi, K., Tasmini, T. \& Ahmad, H. S. Association of -174 G > C interleukin6 gene polymorphism with interleukin- 6 and c-reactive protein levels and obesity: A case-control study among people/residents of Western Indonesia. Med J Malaysia. 74, 400-404 (2019).

47. Tuegel, C. et al. GDF-15, Galectin 3, Soluble ST2, and Risk of Mortality and Cardiovascular Events in CKD. Am J Kidney Dis. 72, 519-528 https://doi.org/10.1053/j.ajkd.2018.03.025 (2018).

48. Nair, V. et al. Growth Differentiation Factor-15 and Risk of CKD Progression. J Am Soc Nephrol. 28, 2233-2240 https://doi.org/10.1681/ASN.2016080919 (2017).

49. Kim, Y., Noren Hooten, N. \& Evans, M. K. CRP Stimulates GDF15 Expression in Endothelial Cells through p53. Mediators Inflamm 2018, 8278039, doi:10.1155/2018/8278039 (2018).

50. Benes, J. et al. The Role of GDF-15 in Heart Failure Patients With Chronic Kidney Disease. Can J Cardiol. 35, 462-470 https://doi.org/10.1016/j.cjca.2018.12.027 (2019).

51. Liu, Y. et al. IL-6 haplotypes, inflammation, and risk for cardiovascular disease in a multiethnic dialysis cohort. J Am Soc Nephrol. 17, 863-870 https://doi.org/10.1681/ASN.2005050465 (2006).

52. Krzanowski, M. et al. Pentraxin 3 as a new indicator of cardiovascularrelated death in patients with advanced chronic kidney disease. Pol Arch Intern Med. 127, 170-177 https://doi.org/10.20452/pamw.3944 (2017).

\section{Figures}




\section{IL6 polymorphism}

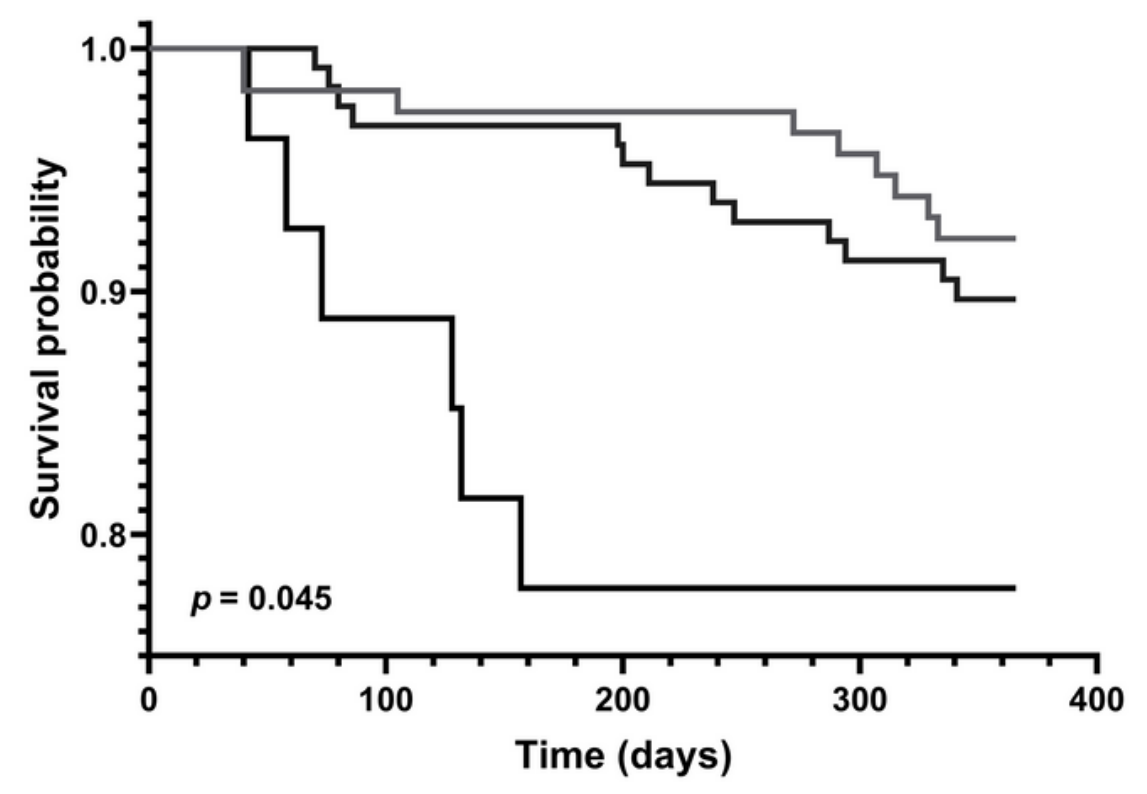

\section{- Genotype CG \\ - Genotype GG \\ - Genotype CC}

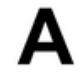

PTX3 polymorphism

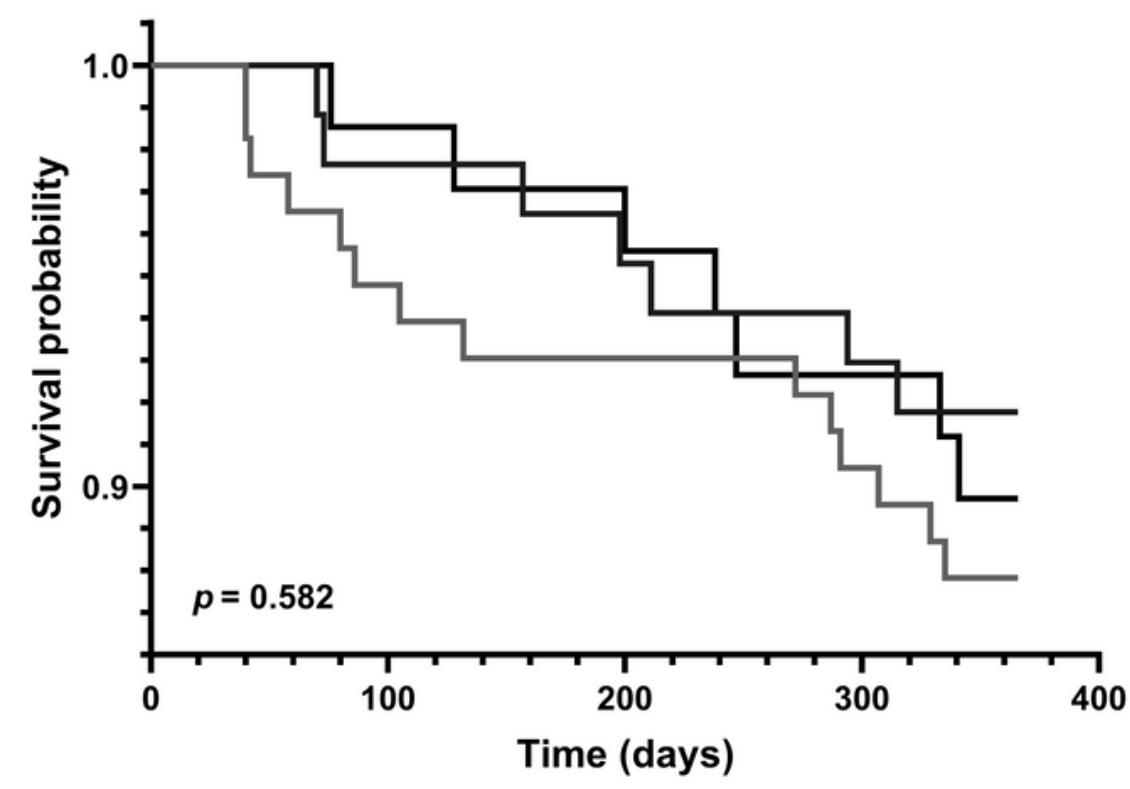

- Genotype AG

- Genotype GG

- Genotype AA

Figure 1

Survival cumulative curves for all-cause mortality in end-stage renal disease patients, by IL6 (A) and by PTX3 polymorphic genotype (B). Survival distribution comparisons between genotypes was performed by the log-rank test. 